\title{
Quality assessment and development in the course of the EFMD CEL programme accreditation
}

\author{
C. Meier, S. Seufert \& D. Euler
}

Institute for Business Education and Educational Management, University of St.Gallen, St.Gallen, Switzerland

\begin{abstract}
This paper reviews the experiences and learnings derived from the European Foundation for Management Development's programme accreditation teChnology-Enhanced Learning (EFMD CEL) programme accreditation. The EFMD CEL quality framework is briefly described, and an overview of the programmes that have pursued accreditation is presented. Subsequently, the evaluation results for the programmes having undergone accreditation/reaccreditation are analysed. This analysis moves from a more aggregated view to a more detailed view, and observations are related to relevant findings in the literature. Also, the key issues and recommendations identified by the auditors for further development of the programmes reviewed are discussed, as are the evaluation results for three programmes that have undergone re-accreditation. Key findings are the following: (1) the quality criteria at the core of the EFMD CEL quality framework are applicable for diverse programmes; (2) the programmes receive differentiated evaluations on the different quality dimensions and quality criteria; (3) auditors' ideas for improvement and recommendations most commonly pertain to the quality dimensions 'Pedagogy' and 'Organization/Culture'; (4) noticeable quality improvements are indeed initiated through the EFDM CEL audit and accreditation process; and (5) quality management is not a one-way street, and slippage with regard to some quality criteria may be observed in re-accreditation results.
\end{abstract}

Keywords accreditation, EFMD CEL, e-learning, quality criteria, quality management.

\section{Introduction}

Quality management comprises all the structures, activities, and procedures directed at the planning, assurance, improvement, or evaluation of the quality of products, processes, or services (Wirth 2005, 132 following DIN EN ISO 8402/DIN EN 9000). This comprises the definition of quality goals and responsibilities, the planning and execution of quality assurance (e.g. evaluation activities), and also the identification of

Accepted: 11 July 2011

Correspondence: Christoph Meier, Institute for Business Education and Educational Management, University of St. Gallen, St.Gallen, 9010, Switzerland. Email: christoph.meier@unisg.ch corrective measures (cf. Harvey \& Green 2000). Quality management is well established in the sector of education and training, and specific standards for quality management in training and education have been developed (e.g. ISO 1999).

Along with the emergence of e-learning over the last 15 or so years, quality issues have become a concern. Numerous 'how to' guides, checklists, management guidelines, and quality frameworks have been developed (for example, Barker 2002; Khan 2005; Moore 2005); quality in e-learning has been discussed on a scholarly level (cf. Ehlers et al. 2005; Ehlers \& Pawlowski 2006; Wirth 2006 or Ãström 2008); and a reference framework specifying critical quality aspects 
concerning e-learning has been established as an international standard (ISO 2005). In addition, several quality frameworks for e-learning that are tied to an accreditation process have been established: the European Foundation for Management Development teChnology-Enhanced Learning (EFMD CEL) accreditation system for e-learning programmes (http:// www.efmd.org/index.php/accreditation-main/cel), the quality label 'European University Quality in eLearning' (UNIQUe) focusing on the use of information and communication technology in higher education (http:// www.qualityfoundation.org/unique-certification), and the MeLQ quality framework for Middle East and Northern Africa (http://melq.hbmeu.ac.ae/).

This paper reviews audit and accreditation results pertaining to the EFMD CEL programme accreditation. EFMD CEL is a quality management system for programmes - both in corporate learning and in higher education - that includes a significant portion of technologically supported learning activities. In mid-2010, 15 programmes had already pursued EFMD CEL accreditation or were still in the process.

On the basis of an analysis of the audit team reports submitted, this paper investigates the following questions:

- Does the EFMD CEL quality management system prove applicable for diverse programmes both in corporate and higher education sectors?

- Which quality areas/criteria proved to be the most/ least challenging for the programmes pursuing accreditation?

- What are key issues and areas for improvement with regard to online learning that emerge from these accreditation processes?

\section{EFMD CEL - programme accreditation for CEL}

Starting in 2005, EFMD has been offering an accreditation for e-learning programmes. The eligibility criteria include, among others, an equivalent of at least $100 \mathrm{~h}$ of learning effort, at least $20 \%$ of which is based on either interactive multimedia or networked interaction. Also, eligible programmes need to display some stability: a first run-through has to have taken place at the time of application (cf. EFMD 2010). The corresponding certificate 'EFMD CEL (programme accreditation for teChnology-Enhanced Learning)' is, by now, well estab- lished in the market (see Table 1 for an overview of programmes that have pursued accreditation).

The EFMD CEL quality management system comprises six quality dimensions: (1) programme profile; (2) pedagogy; (3) economics; (4) technology; (5) organizational-administrative; and (6) cultural, and a total of 30 quality criteria (see Fig 1). This quality framework was derived from research involving expert interviews and a Delphi study, thus tapping the knowledge of experts from both academia and praxis (Seufert $\&$ Euler 2004; Wirth 2005). The large number of quality criteria in the dimension 'Pedagogy' bears witness to the focus on didactic aspects. At the same time, quality criteria cover the input, process, and output dimensions (see Fig 1).

In order to make the EFMD CEL quality criteria observable and assessable, all quality criteria have been operationalized through several steps: (1) specification of data collection/data source; (2) specification of performance indicators; and (3) specification of expected standards (see Table 2).

Next to the conception of quality itself, a professional and trustworthy implementation of this quality management system is important (cf. Wirth 2005, p. 304ff.). With EFMD CEL, this is safeguarded through the independence and mutual control of key roles involved: the audit team evaluating the programmes and the awarding body taking a decision on the accreditation (cf. Wirth 2005 , p. 375 for a detailed description of the roles involved).

The EFMD CEL quality management system combines both internal evaluation (on the basis of a compulsory self-assessment report provided by the applicants) and external evaluation [based on (1) the review of the self- assessment report along with additional documentation; and (2) the audit visit conducted by an audit team]. ${ }^{2}$

The accreditation process is clearly defined and includes 11 distinct steps (see Fig 2). An important aspect of this process are two feedback loops. The representatives of the programme applying for accreditation are expected to commit to steps towards further improvement on the basis of the preliminary audit report (see step 7 in Fig 2). These commitments are taken into consideration when the awarding body takes its decision. Also, in the process of re-accreditation, the developments documented in the interim report (see step 10) and the new self-assessment report become 
Table 1. Overview of the programmes that have pursued European Foundation for Management Development teChnology-Enhanced Learning (EFMD CEL) accreditation.

\begin{tabular}{|c|c|}
\hline Company/institution & Programme \\
\hline $\begin{array}{l}\text { Volkswagen Coaching } \\
\text { GmbH, Germany }\end{array}$ & $\begin{array}{l}\text { Vehicle Electronics, a programme within a larger 'Job Family Development Programme', } \\
\text { targeting specialists and management personnel and supporting organizational transition. }\end{array}$ \\
\hline $\begin{array}{l}\text { Open University Business } \\
\text { School, UK }\end{array}$ & $\begin{array}{l}\text { Professional Diploma in Management, a short, cross-disciplinary, post-graduate programme } \\
\text { delivered in mixed mode, targeting managers of projects/teams/departments and linking } \\
\text { to MBA programmes. }\end{array}$ \\
\hline L'Oréal, France & $\begin{array}{l}\text { L'Oréal e-Strat Challenge, a business strategy simulation organized as a competition between } \\
\text { student teams, serving learning/image building/recruiting purposes. }\end{array}$ \\
\hline $\begin{array}{l}\text { Universitas } 21 \text { Global, } \\
\text { Singapore }\end{array}$ & $\begin{array}{l}\text { Master of Business Administration, a general MBA programme comprising } 17 \text { modules and } \\
\text { offered fully online. }\end{array}$ \\
\hline $\begin{array}{l}\text { University of Maryland } \\
\text { University College, USA }\end{array}$ & $\begin{array}{l}\text { Master's Degree in Distance Education, comprising five core and } 11 \text { specialization modules, } \\
\text { aimed at developing management competence in the field of distance education. }\end{array}$ \\
\hline University of Liverpool & Online Master of Business Administration, comprising eight modules and offered entirely online. \\
\hline $\begin{array}{l}\text { Kavrakoglu } \\
\text { Institute, }\end{array}$ & $\begin{array}{l}\text { Executive MBA, a mixed mode general MBA programme offered also in customized form for } \\
\text { specific companies. }\end{array}$ \\
\hline $\begin{array}{l}\text { SDG - Simuladores e } \\
\text { Modelos de Gestao, } \\
\text { Portugal }\end{array}$ & $\begin{array}{l}\text { Global Management Challenge, a business simulation organized as an annual competition in } \\
\text { cooperation with Strathclyde University. }\end{array}$ \\
\hline Not disclosed & $\begin{array}{l}\text { Online Master in Business Administration, comprising nine modules and addressing mid-level } \\
\text { managers. }\end{array}$ \\
\hline $\begin{array}{l}\text { ESIC Business \& Marketing } \\
\text { School, Spain }\end{array}$ & $\begin{array}{l}\text { A collection of business simulations for different industry sectors that are played as competitive } \\
\text { games and share a common engine and a framework for face-to-face interaction. }\end{array}$ \\
\hline $\begin{array}{l}\text { Caterpillar University, } \\
\text { Switzerland }\end{array}$ & $\begin{array}{l}\text { Sale Effectiveness Process, an initiative of the College of Marketing and Distribution at Cat U, } \\
\text { addressing the external dealer network. }\end{array}$ \\
\hline Not disclosed & $\begin{array}{l}\text { International Master in Business Administration, a mixed-mode programme designed specifically } \\
\text { for target groups in emerging economies (Asia, Africa). }\end{array}$ \\
\hline Société Générale, France & $\begin{array}{l}\text { Citizen Act III, a business competition for students focusing on corporate social responsibility and } \\
\text { serving learning/image building/recruiting purposes. }\end{array}$ \\
\hline
\end{tabular}

MBA, Master of Business Administration.

important. In consequence, the EFMD CEL quality system is geared to encouraging continuous quality improvement.

\section{Quality management on the basis of the EFMD CEL accreditation process: findings and issues}

\section{An overview of evaluation results}

When auditors evaluate programmes as part of the EFMD CEL accreditation process, they are expected to assess each and every criterion, and they are required to employ one of the following four grades: (1) 'above standard'; (2) 'meets standards'; (3) 'below standard'; or (4) 'not applicable'.

Table 3 provides an overview of the assessments that auditors made in the course of the initial accreditation of the programmes listed earlier. ${ }^{3}$ Looking at all quality dimensions compounded, the following observations can be made:
- The quality criteria can almost always be applied. ${ }^{4}$ In the case of two programmes based on simulations, however, a significant number of criteria (e.g. pertaining to assessments) proved not applicable.

- By far, the most frequent assessment is 'meets standard'. Auditors conclude this in almost $2 / 3$ of all cases.

- There are significant differences in the way these programmes are rated by the auditors.

Programmes 3, 6, and 9 (and to a lesser degree, 11) stand out from the crowd with a high number of ratings 'above standard'.

$\bigcirc$ Conversely, programmes $7,10,12$, and 13 received quite a few ratings 'below standard'. However, a significant number of ratings 'below standard' do not automatically lead to a decline of accreditation. While programmes 7 and 10 were accredited, programmes 12 and 13 were not. 


\begin{tabular}{|c|c|c|c|c|c|}
\hline & Input & Process & Output & Perspectives & Quality Perceptions \\
\hline $\begin{array}{l}\text { Programme } \\
\text { Profile }\end{array}$ & $\begin{array}{l}\text { PR1, PR2, } \\
\text { PR3, PR4 }\end{array}$ & & & $\begin{array}{l}\text { - Management } \\
\text { - Learners }\end{array}$ & $\begin{array}{l}\text { Quality as fitness for pur- } \\
\text { pose in respect to institutional } \\
\text { settings and strategic goals }\end{array}$ \\
\hline $\begin{array}{l}\text { Pedagogic } \\
\text { Dimension }\end{array}$ & $\begin{array}{l}\text { PE1, PE6, } \\
\text { PE7 }\end{array}$ & $\begin{array}{l}\text { PE2, PE3, } \\
\text { PE4, PE5, } \\
\text { PE8 }\end{array}$ & PE9, PE10 & $\begin{array}{l}\text { - Learners } \\
\text { - Lecturers/ } \\
\text { Teachers } \\
\end{array}$ & $\begin{array}{l}\text { Learning and transfer success, } \\
\text { strengthening of the self-study com- } \\
\text { petence, pedagogical added value }\end{array}$ \\
\hline $\begin{array}{l}\text { Economic } \\
\text { Dimension }\end{array}$ & E1 & E2 & & - Management & $\begin{array}{l}\text { Sustainable funding and } \\
\text { sustainable added value }\end{array}$ \\
\hline $\begin{array}{l}\text { Technological } \\
\text { Dimension }\end{array}$ & $\mathrm{T} 1, \mathrm{~T} 2$ & $\mathrm{~T} 3, \mathrm{~T} 4$ & T3, T5 & $\begin{array}{l}\text { - Technical Staff } \\
\text { - Lecturers/Teachers } \\
\text { - Learners } \\
\end{array}$ & $\begin{array}{l}\text { Quality as standards-oriented } \\
\text { Zero-tolerance } \\
\text { Quality as added value }\end{array}$ \\
\hline $\begin{array}{l}\text { Organizational } \\
\text { Dimension }\end{array}$ & O1, O3 & $\begin{array}{l}\mathrm{O} 2, \mathrm{O} 4 \\
\mathrm{O} 5\end{array}$ & & $\begin{array}{l}\text { - Management } \\
\text { - Lecturers/Teachers } \\
\text { - Learners } \\
\end{array}$ & $\begin{array}{l}\text { Fitness for purpose in respect to } \\
\text { the set programme and learning } \\
\text { goals, and programme stakeholder }\end{array}$ \\
\hline $\begin{array}{l}\text { Cultural } \\
\text { Dimension }\end{array}$ & & $\begin{array}{l}\text { C1, C2, } \\
\text { C3, C4 }\end{array}$ & & $\begin{array}{l}\text { - Lecturers/Teachers } \\
\text { - Management/Staff }\end{array}$ & $\begin{array}{l}\text { Quality as transformation: } \\
\text { Empowerment for innovations }\end{array}$ \\
\hline
\end{tabular}

Fig 1 The European Foundation for Management Development teChnology-Enhanced Learning (EFMD CEL) quality framework ${ }^{1}$ (Source: EFMD CEL auditor training documentation).

- The auditors found room for improvement with almost all programmes. Only programme 5 was rated 'above standard' or 'meets standard' for all 30 quality criteria.

- The decision not to accredit programmes 12 and 13 rested mainly on a lack of conviction that the organization would successfully take up the recommendations provided by the auditors (one case), and below standard learning processes and a lack of exploitation of the potentials of e-learning (the other case).
It can therefore be concluded that the EFMD CEL quality framework is indeed applicable to programmes both in higher education and in the corporate sector. Also, auditors do not just rubber-stamp the programmes under review. They do employ the different ratings available to them and they do identify areas for improvement in almost all cases. At the same time, the decision to accredit a programme does not simply boil down to counting the number of ratings 'below standard'.

Table 2. Specification of European Foundation for Management Development teChnology-Enhanced Learning quality criteria: data indicators and standards.

\begin{tabular}{|c|c|c|c|c|}
\hline$\#$ & Quality criteria & $\begin{array}{l}\text { Method of } \\
\text { data-collection }\end{array}$ & $\begin{array}{l}\text { Performance } \\
\text { indicators }\end{array}$ & $\begin{array}{l}\text { Auditor quality } \\
\text { evaluation standards }\end{array}$ \\
\hline \multirow[t]{2}{*}{ PE10 } & \multirow{2}{*}{$\begin{array}{l}\text { Assessments follow } \\
\text { the respective } \\
\text { professional } \\
\text { standards } \\
\text { and are valid } \\
\text { to the learning } \\
\text { objectives. }\end{array}$} & Doc & $\begin{array}{l}\text { A list of at least } 2-4 \text { formative } \\
\text { or summative assessments } \\
\text { that could be reviewed ( } 2-3 \\
\text { modules are selected by the } \\
\text { audit team). }\end{array}$ & $\begin{array}{l}\text { A transparent and comprehensible list of } \\
\text { learning modules that allows a grounded } \\
\text { selection. }\end{array}$ \\
\hline & & AT (AV) & $\begin{array}{l}\text { Reflection based on the } 2-3 \\
\text { different assessments and } \\
\text { learning objectives that are } \\
\text { covered by them. }\end{array}$ & $\begin{array}{l}\text { Reflections should be sufficiently described and } \\
\text { comprehensibly explained. The construction } \\
\text { of assessments follows professional standards } \\
\text { if aspects of assessment validity, reliability, } \\
\text { economy, and equality are reflected and } \\
\text { appropriate measurements are conducted. }\end{array}$ \\
\hline
\end{tabular}

Source: EFMD 2006. 


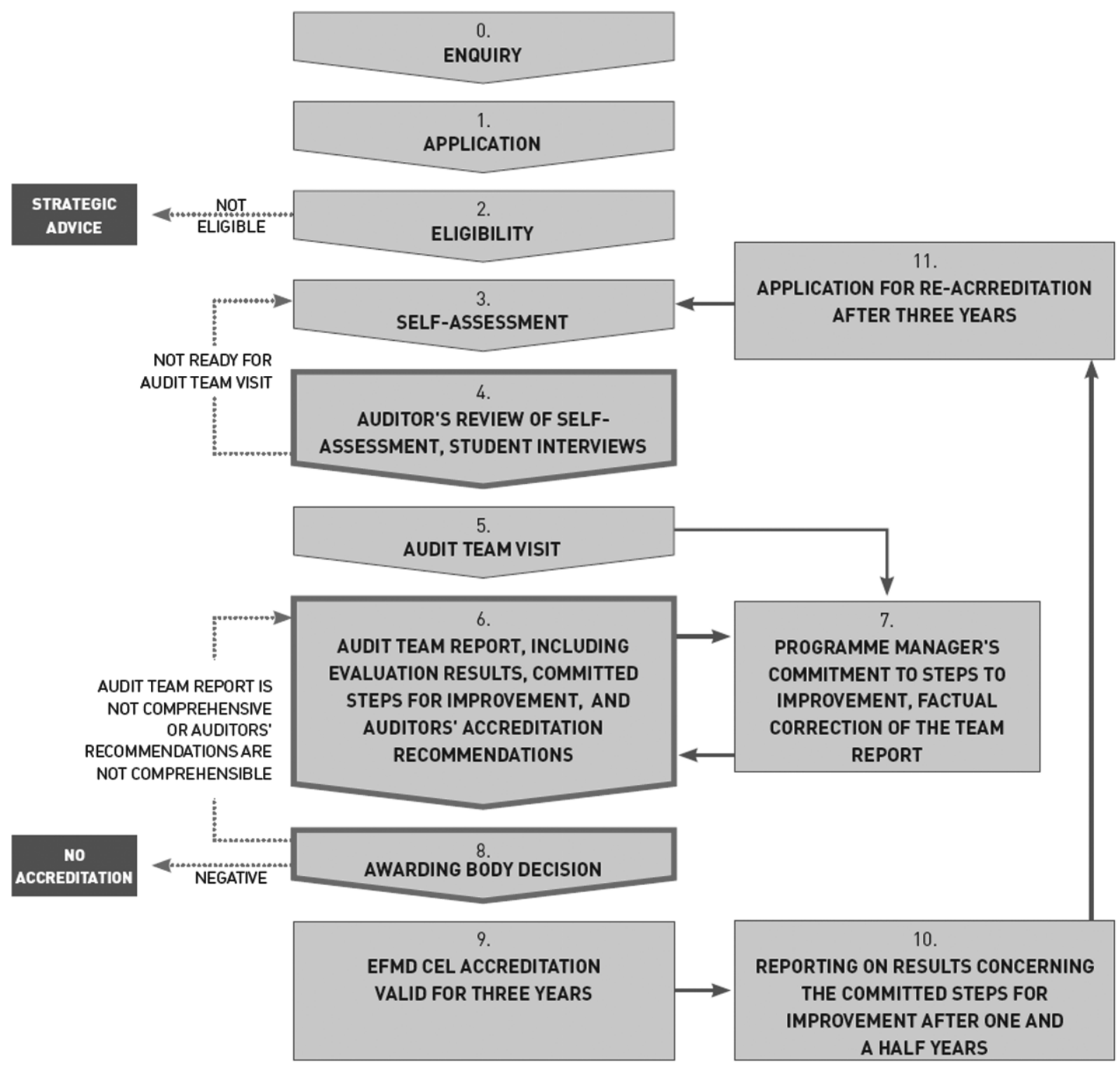

Fig 2 The European Foundation for Management Development teChnology-Enhanced Learning (EFMD CEL) accreditation process (Source: EFMD CEL no date).

Table 3. Number of quality criteria per programme rated above/meets/below standard and not applicable for all quality dimensions compounded. ${ }^{5}$

\begin{tabular}{|c|c|c|c|c|c|c|c|c|c|c|c|c|c|c|c|c|}
\hline \multirow{2}{*}{$\begin{array}{l}\text { Quality } \\
\text { dimension }\end{array}$} & & \multicolumn{13}{|c|}{ Number of ratings by programme } & \multirow{2}{*}{$\begin{array}{l}\text { No. of } \\
\text { ratings }\end{array}$} & \multirow[t]{2}{*}{$\ln \%$} \\
\hline & & 1 & 2 & 3 & 4 & 5 & 6 & 7 & 8 & 9 & 10 & 11 & 12 & 13 & & \\
\hline \multirow{4}{*}{$\begin{array}{l}\text { All criteria in } \\
\text { all quality } \\
\text { dimensions }\end{array}$} & Above standard & - & - & 11 & 4 & 3 & 12 & 3 & 2 & 16 & 3 & 8 & 3 & 1 & 66 & 20 \\
\hline & Meets standard & - & - & 16 & 20 & 27 & 17 & 21 & 23 & 13 & 18 & 21 & 17 & 22 & 215 & 65 \\
\hline & Below standard & - & - & 2 & 2 & 0 & 1 & 6 & 1 & 1 & 7 & 1 & 8 & 7 & 36 & 11 \\
\hline & Not applicable & - & - & 1 & 4 & 0 & 0 & 0 & 4 & 0 & 2 & 0 & 2 & 0 & 13 & 4 \\
\hline
\end{tabular}


Table 4. Number of quality criteria per programme rated above/meets/below standard and not applicable for the different quality dimensions.

\begin{tabular}{|c|c|c|c|}
\hline Quality dimension & & $\begin{array}{l}\text { Number of } \\
\text { ratings }\end{array}$ & $\begin{array}{l}\text { In \% per } \\
\text { dimension }\end{array}$ \\
\hline \multirow[t]{5}{*}{ Programme/profile } & Above standard & 14 & 32 \\
\hline & Meets standard & 24 & 55 \\
\hline & Below standard & 5 & 11 \\
\hline & Not applicable & 1 & 2 \\
\hline & Sum & 44 & 100 \\
\hline \multirow[t]{5}{*}{ Pedagogy } & Above standard & 19 & 17 \\
\hline & Meets standard & 73 & 66 \\
\hline & Below standard & 12 & 11 \\
\hline & Not applicable & 6 & 5 \\
\hline & Sum & 110 & 100 \\
\hline \multirow[t]{5}{*}{ Organization and culture } & Above standard & 26 & 26 \\
\hline & Meets standard & 57 & 58 \\
\hline & Below standard & 12 & 12 \\
\hline & Not applicable & 4 & 4 \\
\hline & Sum & 99 & 100 \\
\hline \multirow[t]{5}{*}{ Economics } & Above standard & 2 & 9 \\
\hline & Meets standard & 18 & 82 \\
\hline & Below standard & 1 & 5 \\
\hline & Not applicable & 1 & 5 \\
\hline & Sum & 22 & 100 \\
\hline \multirow[t]{5}{*}{ Technology } & Above standard & 5 & 9 \\
\hline & Meets standard & 43 & 78 \\
\hline & Below standard & 6 & 11 \\
\hline & Not applicable & 1 & 2 \\
\hline & Sum & 55 & 100 \\
\hline \multirow[t]{5}{*}{ All criteria in all dimensions } & Above standard & 66 & 20 \\
\hline & Meets standard & 215 & 65 \\
\hline & Below standard & 36 & 11 \\
\hline & Not applicable & 13 & 4 \\
\hline & Sum & 330 & 100 \\
\hline
\end{tabular}

Looking at the ratings within the different quality dimensions (see Table 4), the following observations can be made:

- The quality dimensions differ with respect to the distributions of ratings.

$\bigcirc$ The dimensions 'Economics' and 'Technology' feature the most uniform pattern of evaluation and the largest proportion of ratings 'meets standards'.

$\bigcirc$ The highest degree of variation in auditors' evaluations is to be found in the dimensions 'Programme/Profile' and 'Organization \& Culture'. In both cases, a significant number of ratings (almost 1/3) are 'above standard'.

- The percentage of ratings 'below standard' is - with the exception of the dimension
'Economics' - very similar across all quality dimensions.

One conclusion that can be derived from this is that all quality dimensions pose challenges and that auditors find room for improvement with regard to all dimensions: 'Organization \& Culture', 'Programme/ Profile', 'Pedagogy', 'Technology', and, to a lesser degree, 'Economics'.

This kind of analysis can be taken a step further by looking at the ratings for the individual quality criteria (see Table 5):

The following can be observed:

- Across the range of programmes evaluated, the 30 quality criteria received different frequencies of ratings above/meeting/below standard/not applicable. 


\begin{tabular}{|c|c|c|c|c|c|c|c|c|}
\hline \multirow[t]{2}{*}{ Criterion } & \multicolumn{2}{|l|}{$\begin{array}{l}\text { Above } \\
\text { standard }\end{array}$} & \multicolumn{2}{|l|}{$\begin{array}{l}\text { Meets } \\
\text { standard }\end{array}$} & \multicolumn{2}{|l|}{$\begin{array}{l}\text { Below } \\
\text { standard }\end{array}$} & \multicolumn{2}{|l|}{$\begin{array}{l}\text { Not } \\
\text { applicable }\end{array}$} \\
\hline & Frequency & $\%$ & Frequency & $\%$ & Frequency & $\%$ & Frequency & $\%$ \\
\hline PR1 & 4 & 36 & 6 & 55 & 0 & 0 & 1 & 9 \\
\hline PR2 & 2 & 18 & 8 & 73 & 1 & 9 & 0 & 0 \\
\hline PR3 & 4 & 36 & 5 & 45 & 2 & 18 & 0 & 0 \\
\hline PR4 & 4 & 36 & 5 & 45 & 2 & 18 & 0 & 0 \\
\hline PE1 & 3 & 27 & 7 & 64 & 1 & 9 & 0 & 0 \\
\hline PE2 & 2 & 18 & 8 & 73 & 1 & 9 & 0 & 0 \\
\hline PE3 & 0 & 0 & 10 & 91 & 1 & 9 & 0 & 0 \\
\hline PE4 & 4 & 36 & 5 & 45 & 2 & 18 & 0 & 0 \\
\hline PE5 & 2 & 18 & 5 & 45 & 2 & 18 & 2 & 18 \\
\hline PE6 & 1 & 9 & 9 & 82 & 0 & 0 & 1 & 9 \\
\hline PE7 & 2 & 18 & 9 & 82 & 0 & 0 & 0 & 0 \\
\hline PE8 & 1 & 9 & 8 & 73 & 2 & 18 & 0 & 0 \\
\hline PE9 & 3 & 27 & 7 & 64 & 1 & 9 & 0 & 0 \\
\hline PE10 & 1 & 9 & 5 & 45 & 2 & 18 & 3 & 27 \\
\hline 01 & 5 & 45 & 6 & 55 & 0 & 0 & 0 & 0 \\
\hline $\mathrm{O} 2$ & 3 & 27 & 4 & 36 & 3 & 27 & 1 & 9 \\
\hline $\mathrm{O} 3$ & 0 & 0 & 11 & 100 & 0 & 0 & 0 & 0 \\
\hline $\mathrm{O} 4$ & 3 & 27 & 5 & 45 & 3 & 27 & 0 & 0 \\
\hline O5 & 2 & 18 & 9 & 82 & 0 & 0 & 0 & 0 \\
\hline $\mathrm{C} 1$ & 3 & 27 & 6 & 55 & 2 & 18 & 0 & 0 \\
\hline C2 & 3 & 27 & 5 & 45 & 1 & 9 & 2 & 18 \\
\hline C3 & 0 & 0 & 8 & 73 & 2 & 18 & 1 & 9 \\
\hline C4 & 7 & 64 & 3 & 27 & 1 & 9 & 0 & 0 \\
\hline E1 & 1 & 9 & 9 & 82 & 0 & 0 & 1 & 9 \\
\hline E2 & 1 & 9 & 9 & 82 & 1 & 9 & 0 & 0 \\
\hline T1 & 0 & 0 & 10 & 91 & 1 & 9 & 0 & 0 \\
\hline $\mathrm{T} 2$ & 0 & 0 & 9 & 82 & 1 & 9 & 1 & 9 \\
\hline T3 & 2 & 18 & 8 & 73 & 1 & 9 & 0 & 0 \\
\hline T4 & 1 & 9 & 8 & 73 & 2 & 18 & 0 & 0 \\
\hline T5 & 2 & 18 & 8 & 73 & 1 & 9 & 0 & 0 \\
\hline
\end{tabular}

Table 5. Quality criteria and the frequency of their rating as above/meets/below standard and not applicable in programme audits.

The two criteria on which programmes were most often rated 'above standard' are $\mathrm{O} 1$ (command of infrastructure and support) and C4 (leading management is committed to the programme/to e-learning). ${ }^{6}$

$\bigcirc$ Three out of the four criteria in the quality dimension 'Programme/Profile' were rated 'above standard' on four counts, contributing to the highest proportion of ratings 'above standard' in all quality dimensions: PR1 (programme objectives consistent with overall strategy), PR3 (staff is appropriately qualified), and PR4 (students/participants are provided with adequate information).

$\bigcirc$ The two quality criteria in the dimension 'Economics' are rated 'meets standards' almost throughout: E1 (appropriate level of resourcing); E2 (balance between running and advancing the programme).

The two quality dimensions that were most frequently rated 'below standard' are $\mathrm{O} 2$ (competency development policy for staff) and $\mathrm{O} 4$ (continuous quality evaluation).

$\bigcirc$ For business competitions, or business simulations in particular, quality criteria relating to assessments cannot be made fit easily. These programmes account for ten out of a total of 13 ratings of criteria being 'not applicable'.

It can be concluded that for the 11 programmes audited and rated, the CEL quality criteria are rated as 'meets category' most often by the auditors. For some 
criteria, there is a significant number of ratings 'above standard' (C4, O1 and PR1, PR3, PR4 as well as PE4). Ratings as 'below standard' do occur for almost all criteria, but not frequently $(\mathrm{O} 2$ and $\mathrm{O} 4$ receiving this rating most often).

The fairly uniform ratings for the criteria in the dimension 'Economics' as meeting the standards indicates that underestimation of financial resources required does no longer appear to be an issue. This is quite contrary to early phases of the adoption of e-learning, where drastic overruns in costs and budgets were commonplace. However, in the case of one programme not accredited, this was indeed a serious issue and this contributed to the denial of accreditation.

These findings tie in nicely with studies analysing the question why e-learning fails (cf. Romiszowski 2004; Zemsky \& Massy 2004; Seufert 2008). These studies converge on the claim that the success of e-learning does not turn on coming to grips with the challenge of implementing new technologies. Rather, success has to be pursued through an integrated 'systems' approach addressing all the aspects relevant for e-learning. Conversely, a lack of such an integrated approach can lead to serious problems. Zemsky and Massy (2004, p. 29) point to the fact that a focus exclusively on technology can lead to a decreasing support for e-learning in academic institutions. Many earlier technology-based educational innovations suffered from the error of first selecting the technology, then the content and only then giving attention to the practicalities of actually making it work (cf. Romiszowski 2004; Kidney et al. 2007).

What emerges from the audits is that the CELaccredited programmes are indeed following an integrated systems approach. Furthermore, in these programmes, a good balance between innovation and transfer can be observed. Often, new learning approaches have been developed, tested, and propagated with a clear transfer strategy for diffusing good practices into a broader field of application. The focus with these programmes usually is on mid-range innovations that link to supporting structures and current experiences on the basis of a stable business model.

\section{Key issues and recommendations by the audit teams}

The companies and institutions pursuing EFMD CEL accreditation have to invest considerable time, effort, and money in the process. Obtaining accreditation is the paramount goal, of course, and programme representatives may display a fair amount of tension and anticipation during the audit team visit. However, the audit team visiting is not in a position to provide feedback on the likelihood of accreditation as this is for the awarding body to decide. Members of the audit team can and do try to defuse tension and anticipation by framing the audit visit as an opportunity for learning and improvement and by pointing out the opportunity for frank discussion, constructive feedback, and ideas for improvement as important benefits for the applicant institution. In the final chapter to the audit reports entitled 'Feedback Discussion', the audit teams point out the key issues and areas for improvement they have identified.

Not surprisingly, the programmes audited display different strengths and weaknesses. What are key issues and areas for improvement most frequently mentioned by the auditors? The following list orders these by order of frequency with which they appear in the audit team reports, and it also indicates the quality dimension involved.

- Feedback and assessment ('Pedagogy')

$\bigcirc$ Improvements on feedback and assessments (e.g. more formative assessment, assessments more closely tied to learning goals, more individualized feedback to student contributions) are mentioned in six out of 13 reports.

- Faculty development ('Pedagogy', 'Organization/ Culture')

$\bigcirc$ The need for improved competence development among the faculty and staff delivering the programme (e.g. with regard to e-learning) is mentioned in five out of 13 reports.

- Integration of different forms of learning ('Pedagogy')

The need for better integration respectively, coordination of different study units and forms of interaction/learning (e.g. relating to selfstudy units, team assignments, $\mathrm{f}-\mathrm{t}-\mathrm{f}$ seminars) is mentioned explicitly in four reports and implicitly in another two reports.

- Evaluation activities ('Organization/Culture')

$\bigcirc$ In four reports, the auditors point to the need for improved/intensified evaluation activities (e.g. regarding internal processes, 
learning materials, student satisfaction, learning transfer).

- Learner support ('Organization/Culture')

$\bigcirc$ The need for improved learner support (e.g. through extended hours or shorter response times) is mentioned in three reports.

- Interactivity in the learning process ('Pedagogy')

Enhanced interactivity among students and also between students and teachers/trainers is mentioned in three reports as desirable.

- Programme positioning and marketing (pertaining both to 'Programme/Profile' and 'Economics')

$\bigcirc$ In the case of four programmes, the auditors see a need for improvement in the marketing strategies. In three instances, this is related to external target groups; in one instance (corporate learning), this is related to internal target groups.

- Information technology (IT) strategy ('Technology')

$\bigcirc$ The need for improved strategic planning regarding the IT infrastructure required and its ties to didactic scenarios is also the one aspect that was mentioned more than once in the area of technology.

It can be observed that the recommendations provided by the audit teams most often relate to the quality dimensions 'Pedagogy' and 'Organization/Culture'. This indicates that it is in these areas that required changes are most difficult to bring about and take longer to realize (cf. Romiszowski 2004; Zemsky \& Massy 2004; Seufert 2008).

\section{Continuous quality development through accreditation/re-accreditation}

It has already been pointed out that the EFMD CEL quality and accreditation system is geared towards continuous quality improvement. The steps in the process - preparing the self-assessment report, the discussions during the audit team visit, endorsement of the recommendations, and committing to improvements - all contribute to this. To what extent, then, is this general orientation towards continuous quality improvement actually realized in the case of the programmes looked at here? Examples from three programmes that have successfully pursued reaccreditation can serve as illustrations.
For the three programmes having undergone re-accreditation 3 years after their initial accreditation, the following can be observed (see Table 6):

- The overall evaluation scores across all quality dimensions show improvement in all three cases.

- The degree to which there is improvement differs with respect to the different programmes and quality dimensions. While programme 3 shows improvement in each of the quality dimensions, this is not the case for programmes 6 and 7 .

- The evaluation scores for programmes 6 and 7 feature lower ratings in the second compared with the first audit for some quality criteria, in particular in the dimension 'Organization/Culture'. As one member of the audit team participated both in the 1st and in the 2nd audit for all three programme re-accreditations, this points to some slippage.

In the case of one of the programmes undergoing re-accreditation, auditors pointed out the following areas for quality improvement during the first audit:

- A more clearly defined positioning of the programme in the market and a strengthening of the academic claims of the programme through focused research activities;

- An improved coordination of strategic planning and practical realization, for example with regard to the technical infrastructure of the programme; and

- An adaptation of the contracting policies in order to enable the recruitment of renowned academics as teachers in the programme.

In the course of the re-accreditation audit 3 years later, the audit team noted advancement in some of these areas. With regard to research activities, however, little progress was observed and the initial recommendation was repeated in the second audit report.

In the case of another programme, auditors identified the following areas for quality improvement during the first audit:

- A more clearly defined positioning of the programme in the market through an adaptation of the programme title and better involvement of representatives of businesses in an advisory council; 
Table 6. Comparison of evaluation results for first and second accreditations of three programmes.

\begin{tabular}{|c|c|c|c|c|c|c|c|}
\hline \multirow[t]{3}{*}{ Quality dimension } & & \multicolumn{6}{|c|}{ Number of ratings by programme } \\
\hline & & 3 & 3 & 6 & 6 & 7 & 7 \\
\hline & & First accr. & $\begin{array}{l}\text { Second } \\
\text { accr. }\end{array}$ & First accr. & $\begin{array}{l}\text { Second } \\
\text { accr. }\end{array}$ & First accr. & $\begin{array}{l}\text { Second } \\
\text { accr. }\end{array}$ \\
\hline \multirow[t]{4}{*}{ Programme/profile } & Above standard & 2 & 3 & 2 & 2 & 0 & 0 \\
\hline & Meets standard & 2 & 1 & 1 & 2 & 2 & 4 \\
\hline & Below standard & 0 & 0 & 1 & 0 & 2 & 0 \\
\hline & Not applicable & 0 & 0 & 0 & 0 & 0 & 0 \\
\hline \multirow[t]{4}{*}{ Pedagogy } & Above standard & 5 & 6 & 5 & 5 & 0 & 1 \\
\hline & Meets standard & 5 & 4 & 5 & 5 & 8 & 6 \\
\hline & Below standard & 0 & 0 & 0 & 0 & 2 & 3 \\
\hline & Not applicable & 0 & 0 & 0 & 0 & 0 & 0 \\
\hline \multirow[t]{4}{*}{ Organization and culture } & Above standard & 2 & 5 & 5 & 3 & 3 & 1 \\
\hline & Meets standard & 6 & 4 & 4 & 6 & 4 & 6 \\
\hline & Below standard & 1 & 0 & 0 & 0 & 2 & 2 \\
\hline & Not applicable & 0 & 0 & 0 & 0 & 0 & 0 \\
\hline \multirow[t]{4}{*}{ Economics } & Above standard & 0 & 0 & 0 & 1 & 0 & 0 \\
\hline & Meets standard & 1 & 2 & 2 & 1 & 2 & 2 \\
\hline & Below standard & 0 & 0 & 0 & 0 & 0 & 0 \\
\hline & Not applicable & 1 & 0 & 0 & 0 & 0 & 0 \\
\hline \multirow[t]{4}{*}{ Technology } & Above standard & 2 & 2 & 0 & 2 & 0 & 2 \\
\hline & Meets standard & 2 & 3 & 5 & 3 & 5 & 3 \\
\hline & Below standard & 1 & 0 & 0 & 0 & 0 & 0 \\
\hline & Not applicable & 0 & 0 & 0 & 0 & 0 & 0 \\
\hline \multirow[t]{4}{*}{ All criteria in all dimensions } & Above standard & 11 & 16 & 12 & 13 & 3 & 4 \\
\hline & Meets standard & 16 & 14 & 17 & 17 & 21 & 21 \\
\hline & Below standard & 2 & 0 & 1 & 0 & 6 & 5 \\
\hline & Not applicable & 1 & 0 & 0 & 0 & 0 & 0 \\
\hline
\end{tabular}

- Intensified recruitment of students/participants from out of the country in order to achieve greater internationalization of the programme; and

- Development of a marketing strategy and more active marketing of the programme in order to recruit more students.

Again, the auditors observed advancement in some of these areas during the second audit 3 years later. At the same time, they noted that the recommendations regarding more active and systematic marketing of the programme had not been put into practice and that student numbers had decreased slightly - despite an average annual growth rate of about $20 \%$ in the distance education market.

What emerges from this is that through participation in an accreditation process like EFMD CEL, quality improvement can indeed be initiated. At the same time, it becomes apparent that improvement in some quality dimensions requires persistence and continued effort. Slippage may occur. Quality improvement is not a oneway street.

\section{Conclusions}

The EFMD CEL quality framework and accreditation process is based on the philosophy of continuous quality development supported through audits by external experts. By mid-2010, 13 programmes have completed the process. Eleven programmes have been successfully accredited, two programmes have not been accredited. Two more programmes are still engaged in the accreditation process.

The earlier stated analysis of (1) ratings on quality criteria; (2) recommendations by the audit teams; and (3) observations derived from re-accreditations of programmes resulted in the following observations: 
- The quality criteria that are at the core of the EFMD CEL framework prove to be applicable almost throughout and with regard to different programmes in both corporate and higher education sectors.

- The quality criteria are differentiating, and programmes exceed/meet/fall short of the defined standards in different ways and to different degrees.

- The quality dimensions 'Programme/Profile' and 'Organization/Culture' receive the highest ratio of ratings 'above standard'. With the exception of the quality dimension 'Economics', all quality dimensions display almost identical ratios of ratings 'below standard'. Auditors find room for improvement with regard to all quality dimensions.

- The quality criteria most often rated as 'above standard' concern the leading management's support and the infrastructure required for running the programme. The quality criteria most often rated as 'below standard' concern competency development policies for staff and activities to internally evaluate the quality of the programmes.

- Ideas for improvement and recommendations provided by the auditors most commonly pertain to the quality dimensions 'Pedagogy' and 'Organization/ Culture'. Improvements on feedback to students and assessments, on faculty as well as staff development, and concerning the integration of different study units/forms of learning were mentioned most frequently.

- While noticeable quality improvements are indeed initiated through the EFMD CEL audit and accreditation process, this is not necessarily the case. There are instances where recommendations provided by the audit team have not been put into practice by the time a second audit was carried out 3 years later.

- Quality management is not a one-way street. In the case of programmes having undergone re-accreditation, slippage can be observed regarding the ratings for some quality criteria.

- EFMD CEL-accredited programmes mostly follow an integrated systems approach with a good balance between innovation and transfer. Rather than focusing on a single quality dimension (e.g. technology), the focus usually is on mid-range innovations that link to supporting structures and current experiences on the basis of a stable business model.
The research presented here can serve as a model and reference point for further studies that undertake similar analyses for other quality systems. Comparing and contrasting such studies - once they have become available - will allow to review quality systems for e-learning with regard to aspects such as (1) applicability of quality criteria, (2) discriminatory power of quality criteria, (3) the kinds of recommendations for further development emerging from audits, and (4) the effectiveness of such quality systems with regard to supporting continuous quality development. This, in turn, will provide the basis for further development and improvement of such quality systems in the future.

\section{Appendix I. Overview of European Foundation for Management Development teChnology-Enhanced Learning quality criteria ${ }^{7}$}

\section{Programme profile}

Pr1 The objectives of the programme are explicitly enumerated and consistent with and integrated into an overall strategy of institutional development and quality improvement.

$\operatorname{Pr} 2$ The target group of the programme is clearly defined.

Pr3 The staff who designs, manages, runs, and evaluates the programme is appropriately qualified for carrying out their responsibilities. This involves mainly the programme managers, authors, e-tutors, e-moderators, and quality managers.

Pr4 The students/participants are provided with the relevant programme information prior to the start of the programme

\section{Pedagogy}

PE1 The programme's learning objectives are clearly defined and conform to the respective professional pedagogical standards.

PE2 The pedagogical and strategic (added) value of technology-enhanced learning within the programme is explained.

PE3 The structure of the programme allows for a diversity of learning and teaching methods.

PE4 Student/participant interaction with the teaching staff, other students/participants, and/or interactive learning software is an essential characteristic of the programme and is facilitated through a variety of ways. 
PE5 Content making use of technology-enhanced learning is integrated into the programme's curriculum and assessment system.

PE6 There are principles/guidelines regarding the minimum standards for course development and design as well as for the use of third-party contents.

PE7 Instructional materials (e.g. educational software) are reviewed periodically to ensure they meet the programme's objectives and standards.

PE8 Feedback on both the student/participant assignments and questions is constructive and provided in a timely manner.

PE9 The relationship between the learning objectives, assignments, and assessments follows a coherent framework.

PE10 Assessments follow the respective professional standards and are valid to the learning objectives.

\section{Economics}

E1 The institution should demonstrate that the level of overall resourcing is appropriate to achieve the programme objectives.

E2 There is a balance between the running and the advancement of the programme, especially with regard to the technology-enhanced learning components within it.

\section{Technology}

T1 The choice of technologies is based on their appropriateness for the pedagogical concept and takes into account both the students/participants and teaching staff.

T2 There is an IT-strategy with regard to the implementation of technology-enhanced learning that describes the technology currently used, its maintenance, and considerations for future advancement.

T3 The reliability of the technology delivery system is monitored and documented. Service-level agreements for hardware and software reliability are in place and operational.

T4 Educational technology delivery follows best practice recommendations concerning usability and accessibility.

T5 The technology applied allows for the future reuse of content and information, and supports sustainable development.

\section{Organization}

O1 The institution is able to demonstrate the existence and operation of the necessary infrastructure and support for the programme.

O2 There is a competency development policy for the staff involved in the design and running of the courses, especially those with technology-enhanced learning components.

O3 The definition of the work processes for implementing the programme's technology-enhanced learning components is transparent for those involved in the programme's implementation.

O4 The institution conducts a programme of continuous quality evaluation directed towards programme improvement

O5 The institution is responsive to student/participant complaints concerning the courses, especially those with technology-enhanced learning components.

\section{Culture}

C1 There are clear and demanding expectations towards the students/participants and teaching staff, as a major pillar of the programme's learning culture.

C2 The philosophy of change, innovation, and cooperation within the institution, especially with regard to technology-enhanced learning, is stated.

C3 Consideration has been given to issues of workload, compensation, ownership of intellectual property resulting from the programme, and their impact on the staff's commitment and participation.

C4 Commitment of the institution's leading management to support the programme's objectives and implementation, especially with regard to the technology-enhanced learning components within it.

\section{Notes}

${ }^{1}$ An overview of the quality criteria is provided in the Appendix.

${ }^{2}$ Audit teams consist of two experts in the field who have undergone specific auditor training prior to undertaking audits. The audit team reports feature a standardized structure and usually comprise about 25-30 pages.

${ }^{3}$ In order to prevent the identification of programmes and their ratings, the ordering in Table 1 on the one hand and Tables $3-5$ on the other is different.

${ }^{4}$ This, of course, is the task the auditors are set. They are expected to make sense of the quality criteria for the case at hand. However, there are indeed instances where the auditors concluded that individual criteria could not be applied (see the bottom line in Table 3). 
${ }^{5}$ Programmes number 1 and 2 represent 'pilot runs' for the emerging EFMD CEL accreditation process and therefore were not rated relative to a standard. ${ }^{6}$ For an exact wording of the quality criteria, please refer to the overview of the quality criteria provided in the Appendix.

${ }^{7}$ For more extensive documentation on the EFMD CEL quality framework, including quality criteria, indicators, and standards, see the following URL: 'http://www.efmd.org/index.php/accreditation-/cel-programme-accreditationfor-technology-enhanced-learning/EFMD CEL-support-documentation'

\section{References}

Ãström E. (2008) E-learning Quality. Aspects and Criteria for Evaluation of e-Learning in Higher Education. Högskoleverkets Rapportserie 2008:11 R. Swedish National Agency for Higher Education, Stockholm.

Barker K. (2002) Canadian Recommended E-learning Guidelines (CanREGs). FuturEd and CACE (Canadian Association for Community Education), Vancouver. Available at: http://www.futured.com/pdf/CanREGs\%20Eng.pdf (last accessed 10 February 2011).

European Foundation for Management Development (EFMD) (2006) EFMD CEL Criteria, Indicators, and Standards. Available at: http://www.efmd.org/images/stories/ efmd/downloadables/Criteria-Indicators-Standards.pdf (last accessed 14 February 2011).

European Foundation for Management Development (EFMD) (2010) EFMD CELApplication Data Sheet. Available at: http://www.efmd.org/images/stories/efmd/EPAS/ CEL_Application_Data_Sheet_2010.doc (last accessed 14 February 2011).

European Foundation for Management Development (EFMD) (no date) EFMD CEL Introductory Guide. Available at: http://www.efmd.org/images/stories/efmd/ downloadables/EFMD_CEL_Quality_Brochure_Single Pages.pdf (last accessed 8 June 2011).

Ehlers U. \& Pawlowski J., eds (2006) Handbook on Quality and Standardisation in E-Learning. Springer, Berlin, Heidelberg, New York.

Ehlers U., Goertz L., Hildebrandt B. \& Pawlowski J. (2005) Quality in E-Learning. Use and Dissemination of Quality Approaches in European E-Learning. A study by the European Quality Observatory. Cedefop Panorama Series, Vol. 116. Office for Official Publications of the European Communities, Luxembourg.

Harvey L. \& Green D. (2000) Qualität definieren - Fünf unterschiedliche Ansätze. In Qualität Und Qualitätssicherung Im Bildungsbereich: Schule, Sozialpädagogik, Hochschule, Zeitschrift für Pädagogik, 41. (eds U. Helmke, W. Hornstein \& E. Terhart), pp. 17-40. Beiheft, Weinheim.

International Organization for Standardization (ISO) (1999) ISO 10015:1999(E): Quality Management - Guidelines for Training. Available at: http://www.iso.org/iso/iso_ catalogue/catalogue_ics/catalogue_detail_ics.htm?ics1= $03 \& \mathrm{ics} 2=100 \& \mathrm{ics} 3=30 \&$ csnumber $=21231$ (last accessed 20 January 2011).

International Organization for Standardization (ISO) (2005) ISO/IEC 19796-1:2005(E) Information Technology Learning, Education and Training - Quality Management, Assurance and Metrics - Part 1: General Approach. Available at: http://www.iso.org/iso/catalogue_detail? csnumber=33934 (last accessed 20 January 2011).

Khan B.H. (2005) Managing E-Learning: Design, Delivery, Implementation and Evaluation. Information Science Publishing, Hershey.

Kidney G., Gummings L. \& Bohem A. (2007) Towards a quality assurance approach to e-learning courses. International Journal on E-Learning 6, 17-30.

Moore J.C. (2005) The Sloan Consortium Quality Framework and the Five Pillars. The Sloane Consortium. Available at: http://sloanconsortium.org/publications/books/ qualityframework.pdf (last accessed 20 January 2011).

Romiszowski A. (2004) How's the e-learning baby? Factors leading to success or failure of an educational technology innovation. Educational Technology 44, 5-27.

Seufert S. (2008) Innovationsorientiertes Bildungsmanagement. Hochschulentwicklung durch Sicherung der Nachhaltigkeit von eLearning als didaktische Innovation in der Hochschullehre. Habilitationsschrift an der Universität St.Gallen. Veröffentlichung 2008, VS Verlag, Wiesbaden.

Seufert S. \& Euler D. (2004) Nachhaltigkeit von eLearningInnovationen: Ergebnisse einer Delphi-Studies (SCILArbeitsbericht 2). SCIL, St. Gallen. Available at: http:// www.scil.ch/publications/docs/2004-01-seufert-eulernachhaltigkeit-elearning.pdf (last accessed 20 January 2011).

Wirth M. (2005) Qualität eLearning-gestützter Aus- und Weiterbildungsprogramme. Dissertation Universität St. Gallen (Bd. 3119). MVR Druck, Brühl.

Wirth M. (2006) An analysis of international quality management approaches in e-learning: different paths, similar pursuits. In Handbook on Quality and Standardisation in E-Learning [eds U. Ehlers \& J. Pawlowski (Hrsg.)], pp. 97-108. Springer, Berlin, Heidelberg, New York.

Zemsky R. \& Massy W.F. (2004) Thwarted Innovation. What Happened to e-Learning and Why. A Final Report for The Weatherstation Project of The Learning Alliance at the University of Pennsylvania in cooperation with the Thomson Corporation. The Learning Alliance at the University of Pennsylvania, Pennsylvania. Available at: http://www. immagic.com/eLibrary/ARCHIVES/GENERAL/ UPENN_US/P040600Z.pdf (last accessed 10 February 2011). 